\title{
Role of Community Medicine during COVID-19 Pandemic
} E Venkat Rao', Prem Sagar Panda ${ }^{2}$

${ }^{1}$ Professor, Department of Community Medicine, Institute of Medical Sciences \& SUM Hospital, Bhubaneswar, Odisha; ${ }^{2}$ Assistant Professor, Department of Community Medicine, Institute of Medical Sciences \& SUM Hospital, Bhubaneswar, Odisha

\section{Corresponding Author}

Dr Prem Sagar Panda, Department of Community Medicine, Institute of Medical Sciences and SUM Hospital, Bhubaneswar, Odisha - 751003

E Mail ID: drpspanda@gmail.com

\section{Citation}

Rao EV, Panda PS. Role of Community Medicine during COVID-19 Pandemic. Indian J Comm Health. 2021;33(2):242-244. https://doi.org/10.47203/IJCH.2021.v33i02.003

Source of Funding: Nil Conflict of Interest: None declared

\section{Article Cycle}

Received: 02/03/2021; Revision: 14/04/2021; Accepted: 22/05/2021; Published: 30/06/2021

This work is licensed under a Creative Commons Attribution 4.0 International License.

\section{Abstract}

Pandemics have significantly affected economy of each country. Health \& political system have been also drastically affected in each part of the country. To fight against pandemic, it demands multidimensional approaches comprising of various measures like surveillance, containment, isolation \& quarantine, border restriction as well as various socio-political and community measures. Though the entire health workforce is involved at multiple levels, the role of a community medicine/public health expert is maximum in controlling the spread in the community and managing the situation. The community medicine specialists can contribute to the public health as well as health-care services in combating the pandemic. This review has been done for giving an insight of proper utilization of public health services and existing manpower of community medicine. Also, this will channelize our health system and give a direction for combating future public health crisis. Government should utilize the experiences and expertise to manage the pandemic very well.

\section{Keywords}

\section{Pandemics; Quarantine; Public Health; Health Workforce; Community Medicine; Specialization}

\section{Background}

Pandemics have significantly affected economy of each country. Health \& political system have been also drastically affected in each part of the country. To fight against pandemic, it demands multidimensional approaches comprising of various measures like surveillance, containment, isolation \& quarantine, border restriction as well as various socio-political and community measures. In the view of the novel coronavirus disease 2019 (COVID-19) pandemic, which has affected almost all the countries thereby infecting more than 7 million people worldwide, strict measures like isolation \& quarantine needs to be followed and one third of the world's population are now in some form of lockdown or shutdown.(1) Studies have shown that nonpharmaceutical interventions or public health measures have played a major role in the containment of epidemics and pandemics.(2)

In India the numbers of COVID-19 cases are constantly rising, but so far, we have been able to successfully slowdown the ongoing Pandemic from entering into 3rd stage. Though the entire health workforce is involved at multiple levels, the role of a community medicine/public health expert is maximum in controlling the spread in the community and managing the situation. The expertise of Community Medicine specialists has a major role in planning at various levels \& execution and implementation of policies \& guidelines and to interrupt the current pandemic which may result in with high mortality \& morbidity. The expertise of Community physicians can be explained at various levels- i) Community Level ii) District/State Level iii) Central level and the expertise are not always discrete \& can be overlapped at various levels.(3)

\section{Role of Community Medicine during any outbreak:}

The origin of Community Medicine has followed different paths in different parts of the world with a common agreement that community medicine is a linear descendent of public health. While in South Africa community medicine was a conjunct of family medicine and preventive and social medicine, in the United Kingdom the discipline was formed to lead the management of health services in National Health Service (NHS). $(4,5)$ Community medicine in India can be traced back from the year 1946. Bhore report under Health 
Survey and Development Committee recommended a 3 month compulsory training for physicians in preventive and social medicine.(6) Focus then was to impart preventive as well as curative service training to the physicians. Community medicine departments always focused on public health education at undergraduate and postgraduate level.(7) Family Medicine, modern epidemiology, health management, and health promotion are the major concentrations in community medicine along with social sciences/ behavioural sciences, health economics, and environmental, geriatric, mental and occupational health.(8)

Unlike in General medicine, whose primary function is to focus on individual treatment level whereas public health primarily focuses on mass treatment, community prevention and recurrence of a disease. Clinical and public health departments work in coordination when outbreaks occur, understand the epidemiology, slow the spread and investigate the source of infection through contact tracing, thereby help in source reduction and transmission.(9)

During this pandemic community medicine plays a crucial role in minimizing the transmission of infectious diseases. Moreover, Community medicine physician focusses on the following areas like

1. Prepare for field work- Field investigation is conducted before or after conforming increase in cases.

2. Establish the existence of an outbreak comparing the previous data.

3. Verify the diagnosis- By using Medical and/or Laboratory and /or Epidemiological investigation.

4. Define and identify cases

5. Find cases systematically followed by record information-using the epidemiological case sheet.

6. Perform descriptive epidemiology- Identification of population at risk and etiology

7. Develop, evaluate \& refine hypotheses and carry out additional studies

8. Compare with lab and environmental studies

9. Establish control and prevention measures involving in surveillance activity

10. Communicate relevant findings with common people as well as authority.

11. Communicating with public and educating thempreparing IEC materials and training grass-root level workers to educate the community.

12. Contact-Tracing

a) Contact identification

- Preparation of a standard / surveillance case definition for COVID-19.

- Identify potential contacts starting with the case. (Epidemiologist/community physician's visit to the patient's home is mandatory)

b) Contact listing
- All persons considered having significant exposure should be listed as contacts, using the contact form.

- Report any suspicious signs and symptoms such as fever, cold, cough, and difficulty breathing immediately.

c) Contact follow-up

- The epidemiologist / supervisor / contact tracing physician should assemble a competent team involving local supervision and front line workers (ASHA, AWW, ANM \& Supervisors) to track all contacts listed.

Role of Community Medicine in the Crucial Period of COVID-19 Pandemic:

The community medicine specialists can impart their expertise at various levels from community level to central level.

1. At Community Level: (Collaboration with Medical officers, Village leaders \& Frontline workers)

- Through Rural \& Urban Health \& Training Centres; faculties, residents, interns \& undergraduates can create awareness about hand washing, cough etiquette, social distancing, avoiding gathering, use of mask etc.,

- Preparation of IEC materials regarding COVID appropriate behavior and distribution in their field areas.

- Health promotional activities include installation of low cost sanitizer dispensing machine.

- Stop spreading infodemic by providing proper knowledge regarding pandemic.

- Supportive supervision of home and institution quarantine.

- Providing Primary health care services in the field area.

- $\quad$ Finding and training self-help group or local NGOs for stitching mask \&preparation of sanitizers.

2. At District/ State Level: (Collaboration with district administration, various NGOs, Public health specialists, other specialized departments like pulmonary medicine, General medicine \& microbiology)

- Development of district emergency plan and preparedness.

- Be a part of rapid response team and provide valid inputs to the team.

- Active Surveillance, using spot map for case identification, supportive supervision to quarantine centres and ensure COVID appropriate behaviours to be followed.

- Contact tracing, defining containment zones \& ensuring essential health services to containment zones.

- Establishing a helpline number (toll free) for counselling and avoiding fearfulness among common people. 
3. At Central Level: (Collaboration with MOHFW, NGOs, NHM, Various research institutes like ICMR)

- Development of guidelines about the disease concerned, prevention, or containment of the pandemic/halting the transmission by studying the epidemiological trend, formulating the mathematical and epidemiological models, using database from IDSP and other field level activities or research), clinical case finding and laboratory confirmation criteria and disease surveillance

- Policies regarding protecting the rights of medical professionals and other health-care workers, medical indemnity policies during pandemic situation

- Policies regarding inventory/logistics management supply chain

\section{Role of Professional bodies like IAPSM, IPHA \& IAE during} COVID-19 outbreak:(10,11)

A combined task force was constituted taking eminent public health experts from different professional bodies of India like Indian Public Health Association and Indian Association of Preventive \& Social Medicine in April 2020. Further Indian Association of Epidemiologists (IAE) also joined the task force. This was formed with objective of reviewing and compiling the scientific epidemiological literature pertaining to COVID-19 infection in India at various levels, developing common opinion amongst the experts regarding COVID-19 disease epidemiological trends and developing action, wide dissemination of the common statement and action plan with public health experts, health professional associations and other key stakeholders \& with the policy makers at the highest level at centre and state.

1st joint statement was submitted to Hon'ble Prime minister, union health minister, NITI AYOG, secretary (Health \& Family Welfare \& Department of Health Research) on 11th April 2020. Similarly, the 2nd joint statement was submitted on 25th May 2020. It has following recommendations:

1. Constitution of panel of interdisciplinary public health experts and social scientists at various levels.

2. Sharing of data in public health forum.

3. Lift lockdown, replace with cluster restriction or containment.

4. Resumption of all routine health services.

5. Source reduction measures to be adopted.

6. Ensure physical distancing with social bonding.

7. Sentinel \& Active surveillance.

8. Test, trace, track (3T) \& isolate cases with marked scaling up.

9. Strengthening intensive care capacity.

10. Optimal PPE for frontline health care workers.

11. Strengthening the public health system/discipline.

3rd Joint statement was given to government in 25th August 2020 with a motive to support the Government of India in formulating evidence-based policy for prevention
\& control of COVID-19 pandemic in India and it had certain recommendations regarding:

1. No lockdown or shutdown, only cluster restriction

2. Quarantine \& isolation policy

3. Pragmatic testing

4. Immediate resumption of comprehensive health-care services

5. Protection of high risk population

6. Continue preventive measures like physical distancing, mask use \& hand washing

7. ILI \& SARI surveillance

8. Periodic sero-surveillance

9. Opening of educational institutions with certain guidelines

10. Role of vaccine in ongoing pandemic

11. Increase health expenditure to $5 \%$ of GDP

12. Formation of public health cadre at national \& state levels.

\section{Conclusion}

It's the high time all sectors along with community involvement should come forward to fight against this pandemic using appropriate technology. The role of Community Medicine has always been immense during any pandemic. The Community physicians have to play the key role in developing and sustaining the response mechanism. Also the central and state government should involve the community physicians in various High Level Expert Groups and seek their expertise.

\section{References}

1. Lee JQ, Loke $\mathrm{W}, \mathrm{Ng} \mathrm{QX}$. The role of family physicians in a pandemic: a blueprint. In Healthcare 2020; 8(3):198. Multidisciplinary Digital Publishing Institute.

2. Aledort JE, Lurie N, Wasserman J, Bozzette SA. Non-pharmaceutical public health interventions for pandemic influenza: An evaluation of the evidence base. BMC Public Health 2007;7:208.

3. Giri PP, Bhatia V. Time to win the war against COVID-19: How and where community medicine professionals can contribute? Indian J Community Fam Med 2020;6:9-12.

4. Kark JD, Abramson JH. Sidney Kark's contributions to epidemiology and community medicine. Int J Epidemiol 2003;32:882-4.

5. Warren MD. The creation of the faculty of community medicine (now the public health medicine) of Royal Colleges of Physicians of United Kingdom. J Public Health Med 1997;19:93-105.

6. Bhore Committee [Internet]. 1946. Available from: http://www.nihfw.org/NDC/DocumentationServices/Committe_a nd_commission.html

7. Negandhi H, Sharma K, Zodpey SP. How can departments of community medicine shape the future of public health education in India? Indian J Public Health 2010;54:184-9.

8. Kumar R. Development of community medicine sub-specialities. Indian J Commu Med 2005;30:43.

9. COVID-19 Stories: The Role of Public Health. MESA County Public Health. Url: https://health.mesacounty.us/covid-19-stories-therole-of-public-health/.

10. 2nd Joint Statement on CoVID-19 Pandemic in India - Public Health Approach for COVID-19 Control by IAPSM, IPHA \& IAE Url:

11. 3rd Joint Statement on CoVID-19 Pandemic in India - Public Health Approach for COVID-19 Control by IAPSM, IPHA \& IAE. UrI: https://www.iphaonline.org/wp-content/uploads/2020/08/3rdJoint-Statement-of-IPHA-IAPSM-and-IAE-for-COVID-19containment-plan August-25-2020.pdf 